\title{
Meningkatkan Kapasitas Produksi dengan Capacity Planning (Studi pada PT XYZ)
}

\author{
Asni Mustika Rani \\ Fakultas Ekonomi dan Bisnis-Manajemen, Universitas Islam Bandung (UNISBA) \\ asnimustika@unisba.ac.id
}

\begin{abstract}
ABSTRAK
Pertumbuhan Industri Pengolahan Alas Kaki di Kota Bandung mengalami peningkatan 1\% pada tahun 2017 (Portal Data Kota Bandung, 2017). PT XYZ memproduksi alas kaki berupa sandal jepit yang bahan dasar sponge. Sandal jepit ini diproduksi dengan jumlah dan model berdasarkan pesanan dari konsumen. Pada tahun 2018 perusahaan hanya dapat memenuhi permintaan konsumen sebesar 76,74\%, padahal permintaan konsumen terus meningkat. Karena itu penting bagi perusahaan untuk meningkatkan kapasitas produksi sandalnya dengan memperhatikan permintaan konsumen. Penelitian ini menggunakan pendekatan deskriptif kuantitatif, dengan menerapkan metode capacity planning base case, expansionist dan wait and see. Hasil dari penelitian ini adalah perusahaan sebaiknya menggunakan strategi expansionist atau wait and see dengan menambah 1 mesin pada tahun ke-3 agar dapat meningkatkan kapasitas produksi sandal sesuai dengan kenaikan permintaan konsumen.
\end{abstract}

Kata Kunci: manajemen operasi, kapasitas produksi, capacity planning.

\section{ABSTRACT}

The growth of the Footwear Processing Industry in Bandung increased by 1\% in 2017 (Portal Data Bandung, 2017). PT XYZ manufactures footwear in the form of sandals which are basic ingredients of sponge. These sandals are produced with quantities and models based on orders from consumers. In 2018 the company can only meet consumer demand of $76.74 \%$, even though consumer demand continues to increase. Therefore it is important for companies to increase their sandals production capacity by paying attention to consumer demand. This study uses a quantitative descriptive approach, by applying the base case capacity planning method, expansionist and wait and see. The results of this study are that companies should use an expansionist or wait and see strategy by adding 1 machine in the 3rd year in order to increase their slipper production capacity according to the increase in consumer demand.

Keywords: operation management, production capacity, capacity planning.

\section{PENDAHULUAN}

\section{Latar Belakang}

Permintaan produk fesyen seperti pakaian, aksesoris, tas, topi, maupun sandal di Kota Bandung selalu tinggi, maka dari itu produsen produk fashion harus bisa memenuhi permintaan juga keinginan dari konsumen yang selalu berubah-ubah. Perusahaan harus dapat mempertahankan konsistensinya untuk bertahan dalam industri fesyen yang dinamis ini. Pemenuhan permintaan kosumen baik dari segi kuantitas, kualitas maupun ketepatan waktu menjadi tuntutan yang harus diberikan oleh perusaaan. Apabila faktor kuantitas, kualitas dan ketepatan waktu dapat terpenuhi, maka konsumen diharapkan loyal terhadap perusahaan, dan jika konsumen sudah loyal pada perusahaan, itu artinya perusahaan sudah memiliki keunggulan dibandingkan dengan pesaing-pesaingnya (Rani, 2016:1). 
PT XYZ merupakan salah satu perusahaan yang bergerak di Industri Pengolahan Alas Kaki yang memproduksi sandal. Sandal yang dibuat menggunakan bahan utama berupa sponge, namun dibuat dengan model yang disesuaikan dengan permintaan konsumen. Perusahaan ini menggunakan sistem produksi by order atau memproduksi sandal sesuai desain dan sejumlah pesanan konsumen. Kendala utama dari perusahaan ini adalah produksi yang fluktuatif karena tergantung pesanan dan kurangnya kapasitas produksi sandal. Berikut ini tabel produksi sandal dan permintaan sandal pada tahun 2017:

Tabel 1. Produksi dan Permintaan Sandal PT XYZ Tahun 2017

\begin{tabular}{|c|l|c|c|c|}
\hline NO & BULAN & JUMLAH & JUMLAH & \\
\hline 1 & Januari & 3060 & 5000 & -1940 \\
\hline 2 & Februari & 5060 & 6250 & -1190 \\
\hline 3 & Maret & 7380 & 10000 & -2620 \\
\hline 4 & April & 5620 & 10000 & -4380 \\
\hline 5 & Mei & 9080 & 10000 & -920 \\
\hline 6 & Juni & 10860 & 12000 & -1140 \\
\hline 7 & Juli & 8640 & 12000 & -3360 \\
\hline 8 & Agustus & 5880 & 8000 & -2120 \\
\hline 9 & September & 1062 & 2000 & -938 \\
\hline 10 & Oktober & 12350 & 15000 & -2650 \\
\hline 11 & Nopember & 11477 & 15000 & -3523 \\
\hline 12 & Desember & 1836 & 2000 & -164 \\
\hline \multicolumn{2}{|c|}{ TOTAL } & $\mathbf{8 2 3 0 5}$ & $\mathbf{1 0 7 2 5 0}$ & $\mathbf{- 2 4 9 4 5}$ \\
\hline
\end{tabular}

Sumber: data perusahaan (2018)

Berdasarkan tabel 1 di atas, terlihat bahwa dalam tiap bulan perusahaan memiliki jumlah permintaan yang berubah-ubah, dan perusahaan tidak dapat memenuhi permintaan secara penuh. Pada tahun 2017 terdapat total permintaan sandal sebesar 107.250 pasang sandal, sedangkan jumlah produksi sebesar 82.305 pasang sandal, terdapat selisih produksi sebanyak 24.945 pasang sandal yang tidak dapat dipenuhi. Selain itu permintaan sandal model baru dari konsumen semakin variatif, yang menyebabkan perusahaan harus menambah fasilitas baru sebagai penunjang proses produksi. Jika permintaan sandal tersebut semakin meningkat, maka kapasitas produksi juga harus meningkat. Kurangnya kapasitas produksi perusahaan menyebabkan tidak terpenuhinya permintaan konsumen, yang juga menyebabkan hilangnya kesempatan perusahaan untuk memperoleh keuntungan lebih.

Dengan adanya permasalahan tersebut maka dilakukan penelitian untuk merencanakan kapasitas produksi sandal. Capacity planning atau perencanaan kapasitas adalah proses untuk merencanakan kapasitas sistem agar dapat memenuhi kebutuhan saat ini serta dapat mengantisipasi pertumbuhan kebutuhan di masa yang akan datang. Secara teknis, capacity planning berarti merencanakan resource atau sumber daya yang dibutuhkan suatu sistem untuk beroperasi. 


\section{Identifikasi Masalah}

Perencanaan kapasitas produksi menjadi hal penting harus dilakukan perusahaan demi memenuhi permintaan konsumen. Berdasarkan identifikasi masalah tersebut, penelitian ini mencoba untuk menganalisis bagaimana perencanaan kapasitas produksi sandal di PT XYZ dengan menggunakan metode capacity planning dengan membandingkan strategi base case, expansionist dan wait and see.

\section{Rumusan Masalah}

Berdasarkan identifikasi masalah diatas maka permasalahan yang dibahas dalam penelitian ini adalah bagaimana perencanaan kapasitas produksi sandal di PT XYZ agar dapat meningkatkan kapasitas produksi sandal.

\section{LANDASAN TEORI}

\section{Kapasitas}

Kapasitas merupakan salah satu bagian dari kesepuluh keputusan penting dalam manajemen operasi. Kapasitas adalah tingkat kemampuan perusahaan untuk memproduksi suatu barang atau jasa yang didukung dengan tersedianya fasilitas berupa tenaga kerja dan peralatan, dan biasanya dinyatakan dalam jumlah output yang dapat dihasilkan untuk periode waktu tertentu.

Pengertian kapasitas harus dilihat dari tiga perspektif agar lebih jelas. Terdapat tiga perspektif waktu dalam kapasitas (Kusuma, 2004:113) yaitu: (1) Kapasitas desain (design capacity), menunjukkan output maksimum pada kondisi ideal dimana tidak terdapat konflik penjadwalan, tidak ada produk yang rusak atau cacat, perawatan hanya yang rutin, dan sebagainya. (2) Kapasitas efektif (effective capacity), menunjukkan output maksimum pada tingkat operasi tertentu. Pada umumnya kapasitas efektif lebih rendah daripada kapasitas desain. (3) Keluaran aktual (actual output), menunjukkan output nyata yang dapat dihasilkan oleh fasilitas produksi. Kapasitas aktual sedapat mungkin harus diusahakan sama dengan kapasitas efektif.

Efisiensi dan utilisasi merupakan suatu pengukuran sistem yang bermanfaat untuk kapasitas. Utilization is simply the percent of design capacity actually achieved and effeciency is the percent of effective capacity actually achieved (Heizer dan Render 2011:315).

\section{Perencanaan Kapasitas}

Dalam kaitannya dengan konsep kapasitas maka perencanaan kapasitas berusaha untuk mengintegrasikan faktor-faktor produksi untuk meminimumkan biaya fasilitas produksi. Capacity planning is the process of establishing the output rate that can be achieved by a facility (Reid dan Sanders, 2011:316). Capacity planning memiliki peranan yang sangat sentral untuk mewujudkan tujuan perusahaan dalam jangka panjang. Hal ini disebabkan karena capacity planning akan menentukan seberapa besar tingkat output yang mampu dihasilkan oleh perusahaan untuk memenuhi permintaan pasar. 
Perencanaan untuk kapasitas merupakan sesuatu yang penting jika sebuah perusahaan ingin tumbuh dan mengambil keuntungan dalam memenuhi permintaan. Keputusan-keputusan yang menyangkut kapasitas produksi harus mempertimbangkan faktor-faktor ekonomis fasilitas produksi tersebut termasuk di dalamnya efisiensi dan utilisasinya. Faktor-faktor yang mempengaruhi pembentukan kapasitas efektif adalah rancangan produk, kualitas bahan yang digunakan, sikap dan motivasi tenaga kerja, perawatan mesin/fasilitas, serta rancangan pekerjaan (Kusuma, 2004:114).

Perencanaan kapasitas yang melibatkan investasi pada penambahan peralatan dan fasilitas baru, dikategorikan pada perencanaan jangka panjang, biasanya direncanakan untuk memenuhi kapasitas setidaknya untuk tiga tahun kedepan.

\section{Proses Perencanaan Kapasitas}

Terdapat empat langkah umum yang dapat membantu membuat keputusan mengenai kapasitas (Krajewski, Ritzman dan Malhotra, 2010 : 226), yaitu: (1) Estimasi kebutuhan kapasitas. Seandainya kapasitas diasumsikan sebagai jumlah mesin yang ada dalam suatu operasi, maka untuk menentukan kebutuhan kapasitas (jumlah mesin yang dibutuhkan) kedepannya dapat dilakukan dengan menggunakan rumus. Apabila produk yang dihasilkan hanya satu jenis:

$$
M=\frac{D p}{N\left[1-\left(\frac{C}{100}\right)\right]}
$$

\footnotetext{
Keterangan:

$\mathrm{M}=$ Jumlah mesin yang dibutuhkan

$\mathrm{D}=$ Jumlah permintaan yang diramalkan per tahun

$\mathrm{P}=$ Waktu proses per jam per unit

$\mathrm{N}=$ Jumlah jam kerja mesin per tahun

$\mathrm{C}=$ Capacity cushion yang diinginkan
}

(2)Identifikasi gap. Gap kapasitas, adalah selisih (positif ataupun negatif) antara ramalan permintaan dengan kapasitas yang ada saat ini. Untuk mengatasi gap kapasitas, perlu dilakukan pengembangan alternatif. Salah satu alternatif adalah base case, yaitu tidak melakukan apa-apa dan kehilangan order permintaan yang melebihi kapasitas saat ini. (3) Evaluasi alternatif. Alternatif yang dipilih harus dievaluasi secara kualitatif maupun kuantitatif. Evaluasi secara kualitatif terutama memperhatikan masalah yang berkaitan dengan dampak perusahaan secara keseluruhan. Sedangkan secara kuantitatif, evaluasi lebih terfokus pada besar keuntungan yang akan diperoleh bila suatu alternatif diterapkan. Besarnya keuntungan ini biasanya diperoleh dengan cara menghitung arus kas.

\section{METODE PENELITIAN}

\section{Perhitungan Capacity Planning}

Langkah-langkah Perhitungan capacity planning adalah sebagai berikut: (1) Mengumpulkan data dari objek penelitian dengan melakukan observasi dan wawancara, (2) Mengolah data yang diperoleh untuk mendapatkan kapasitas produksi PT XYZ yang tersedia saat ini, (3) Meramalkan permintaan untuk tiga tahun kedepan dengan menggunakan metode 
Time Series. (4) Melakukan uji ketelitian dari peramalan yang dilakukan dengan mencari error terkecil dengan menghitung nilai:

$$
\begin{gathered}
M S E=\frac{\sum E_{t}^{2}}{n} \\
M A D=\frac{\sum\left[E_{t}\right]}{n} \\
M A P E=\frac{\left(\sum\left|E_{t}\right| / D_{t}\right) \times 100}{n}
\end{gathered}
$$

(1)Menentukan metode peramalan terbaik kemudian menggunakanya untuk permintaan tiga tahun kedepan. (2) Setelah didapat peramalan permintaan untuk tiga tahun kedepan, dengan rumus:

$$
M=\frac{D p}{N\left[1-\left(\frac{C}{100}\right)\right]}
$$

(3)Dari data yang ada selanjutnya dicari perbedaan antara kapasitas tersedia dengan kapasitas yang dibutuhkan, kemudian dicari alternatif untuk menutupi perbedaan tersebut antara lain melalui strategi: (a) Base case, yaitu tidak melakukan perubahan apapun pada kapasitas, sehingga permintaan yang melebihi kapasitas tidak akan dapat terpenuhi; (b) Expansionist, yaitu kapasitas yang direncanakan naik secara bertahap, tidak sering dan selalu melebihi nilai permintaan shingga dapat meminimalkan resiko kehilangan keuntungan yang disebabkan terbatasnya kapasitas; dan Wait and See, yaitu strategi untuk meningkatkan kapasitas sesuai dengan peningkatan permintaan sehingga apabila terjadi peningkatan permintaan maka untuk mengisi kekurangan kapasitas sementara waktu perusahaan menerapkan strategi jangka pendek seperti penggunaan waktu lembur, tenaga kerja tambahan, subkontrak, dan lain-lain, sebelum benar-benar melakukan penambahan kapasitas.

\section{Perhitungan Alternatif Keputusan}

Langkah-langkah Perhitungan Alternatif Keputusan adalah sebagai berikut: (1)Melakukan evaluasi kuantitatif untuk mencari alternatif terbaik bagi perkembangan perusahaan di waktu yan g akan datang yaitu evaluasi dengan menggunakan decision tree untuk mengetahui tingkat perubahan aliran kas sepanjang waktu peramalan dibandingkan bila tidak melakukan apapun (base case); (2) Menghitung Net Present Value (NPV) dari investasi alternatif yang telah dilakukan; dan (3) Menentukan alternatif yang sesuai dan paling menguntungkan bagi perusahaan.

\section{PEMBAHASAN}

PT XYZ merupakan perusahaan yang memproduksi sandal berdasarkan pesanan dari konsumen. Dalam melakukan proses produksinya, hingga saat ini perusahaan memiliki sembilan jenis mesin.

Perusahaan PT XYZ memiliki rata-rata pegawai sebanyak 20-25 orang. Proses produksi sandal ini sebagian besar menggunakan mesin yang digunakan secara manual atau menggunakan tenaga manusia. Setiap bagian produksi dikerjakan oleh satu orang atau maksimal dua orang. Dengan jumlah mesin yang dimiliki perusahaan saat ini, PT XYZ

ISSN: 1829-8680 E-ISSN: 2599-0039 
memiliki design capacity produksi sebanyak 400 pasang sandal per hari. Jika disesuaikan dengan kemampuan tenaga kerja dalam memproduksi sandal dan permintaan dari konsumen, rata-rata effective capacity sebanyak 300 pasang sandal per hari.

Perusahaan ini memiliki jam kerja efektif selama 8 jam per hari, jika permintaan sandal sedang banyak, maka diadakan lembur maksimal 3 jam sehingga mampu memproduksi 350400 pasang sandal. Ketika permintaan sandal sedang menurun, terdapat mesin dan jam kerja menganggur. Berikut ini adalah data permintaan sandal dan jumlah produksi PT XYZ pada tahun 2010-2012:

Tabel 2. Permintaan Sandal PT XYZ Tahun 2010-2012

\begin{tabular}{|l|c|c|c|c|c|c|}
\hline \multirow{2}{*}{} & \multicolumn{2}{|c|}{$\mathbf{2 0 1 5}$} & \multicolumn{2}{c|}{$\mathbf{2 0 1 6}$} & \multicolumn{2}{c|}{2017} \\
\cline { 2 - 7 } & $\begin{array}{c}\text { Jumlah } \\
\text { Produksi }\end{array}$ & $\begin{array}{c}\text { Jumlah } \\
\text { Permintaan }\end{array}$ & $\begin{array}{c}\text { Jumlah } \\
\text { Produksi }\end{array}$ & $\begin{array}{c}\text { Jumlah } \\
\text { Permintaan }\end{array}$ & $\begin{array}{c}\text { Jumlah } \\
\text { Produksi }\end{array}$ & $\begin{array}{c}\text { Jumlah } \\
\text { Permintaan }\end{array}$ \\
\hline Januari & 2754 & 3000 & 2195 & 2500 & 3060 & 5000 \\
\hline Februari & 4554 & 5000 & 3595 & 4000 & 5060 & 6250 \\
\hline Maret & 6042 & 6250 & 5035 & 5250 & 7380 & 10000 \\
\hline April & 5058 & 6250 & 4215 & 4250 & 5620 & 10000 \\
\hline Mei & 7172 & 7500 & 6010 & 6250 & 9080 & 10000 \\
\hline Juni & 7774 & 7800 & 7145 & 7500 & 10860 & 12000 \\
\hline Juli & 8776 & 10000 & 6480 & 7500 & 8640 & 12000 \\
\hline Agustus & 5292 & 6250 & 4410 & 4410 & 5880 & 8000 \\
\hline September & 3957 & 4000 & 797 & 800 & 1062 & 2000 \\
\hline Oktober & 860 & 900 & 1200 & 1200 & 12350 & 15000 \\
\hline Nopember & 650 & 700 & 1608 & 1800 & 11477 & 15000 \\
\hline Desember & 1150 & 1500 & 2377 & 3000 & 1836 & 2000 \\
\hline & $\mathbf{5 4 0 3 9}$ & $\mathbf{5 9 1 5 0}$ & $\mathbf{4 5 0 6 7}$ & $\mathbf{4 8 4 6 0}$ & $\mathbf{8 2 3 0 5}$ & $\mathbf{1 0 7 2 5 0}$ \\
\hline
\end{tabular}

Sumber: Analisis Penulis

\section{Peramalan}

Permintaan sandal PT XYZ pada masa lalu berfluktuasi, memiliki pola data musiman dan tren. Dikarenakan bentuk pola data tersebut, maka dihitung peramalan produksi dengan membandingkan antara metode Exponential Smoothing Seasonal Variation in Data dengan metode Simple Regression.

Tabel 3. Perbandingan Metode Peramalan

\begin{tabular}{|l|c|c|}
\hline & $\begin{array}{c}\text { Metode Exponential } \\
\text { Smoothing Seasonal } \\
\text { Variation in Data } \alpha=0,2\end{array}$ & Simple Regression \\
\hline Mean Square Error & 7243379,097 & 12944870 \\
\hline Mean Absolute Deviation & 2039,82495 & 3033,77 \\
\hline Mean Absolute Percentage Error & 0,007075628 & 1,19 \\
\hline
\end{tabular}

Sumber: Analisis Penulis

Berdasarkan perhitungan error untuk membandingkan metode peramalan permintaan sandal, maka PT XYZ untuk tahun 2018-2020 yang akan digunakan dalam menghitung 
perencanaan kapasitas adalah dengan menggunakan metode exponential smoothing, seasonal variation in data. berikut:

Dalam kumulatif, hasil peramalan permintaan sandal tiap tahunnya adalah sebagai

Tabel 4. Hasil Peramalan dalam Kumulatif

\begin{tabular}{|c|c|}
\hline Tahun & Data Forecast (Permintaan) \\
\hline 2018 & 56886 \\
\hline 2019 & 50500 \\
\hline 2020 & 80042 \\
\hline
\end{tabular}

Sumber: Analisis Penulis

Hasil peramalan ini akan dijadikan acuan dalam merencakanan kapasitas produksi sandal selama tiga tahun ke depan dengan menerapkan strategi expansionist, strategi wait and see, dan strategi base case.

\section{Estimasi Kebutuhan Kapasitas}

Dari seluruh mesin yang ada di perusahaan, terdapat dua mesin utama yang mampu memberikan kenaikan produksi yang signifikan yaitu mesin pon dan mesin press pemanas. Mesin pon merupakan mesin yang digunakan untuk membuat pola sandal, dan mesin press pemanas adalah mesin pemanas sponge yang berfungsi untuk merapatkan pori-pori sponge. Dua mesin itu akan dihitung menjadi satu set mesin.

Rata-rata output per hari adalah 300 pasang sandal dan kapasitas desain per hari adalah 400 pasang sandal per hari, tingkat utilitasnya adalah 70\%, dan capacity cushion adalah 30\%. Tetapi perusahaan memiliki kebijakan sendiri, yaitu penentuan capacity cushion $20 \%$ karena perusahaan cukup untuk menutup produksi jika sewaktu-waktu ada permintaan besar.

Maka strategi wait and see dalam perhitungannya akan menggunakan capacity cushion 0\% jika ditemukan sesuai dengan peramalan permintaan, PT XYZ tidak perlu menyia-nyiakan pembelian mesin dan hanya menggunakan kebutuhan yang ada, sedangkan jika ditemukan permintaan melebihi kapasitas, maka pertama-tama yang akan dilakukan adalah lembur, tetapi jika masih belum puas, maka PT XYZ akan membeli mesin sesuai dengan peningkatan permintaan yang terjadi. Dan yang terakhir adalah strategi base case untuk mempertahankan jumlah mesin yang ada dan menggunakan lembur untuk memenuhi permintaan yang melebihi kapasitas normal.

Perhitungan jumlah mesin yang dibutuhkan: (1) Strategi Expansionist, dengan capacity cushion 20\% Tahun $2018 M=\frac{56886 \times 0,032}{6 \times 300\left[1-\left(\frac{0,2}{100}\right)\right]}=1,013$ set $=1$ set, Tahun $2019 M=$ $\frac{50500 \times 0,032}{6 \times 300\left[1-\left(\frac{0,2}{100}\right)\right]}=0,899$ set $=1$ set, Tahun $2020 M=\frac{80042 \times 0,032}{6 \times 300\left[1-\left(\frac{0,2}{100}\right)\right]}=1,426$ set $=2$ set. (2) Strategi Wait and See, dengan capacity cushion 0\% Tahun $2018 M=\frac{56886 \times 0,032}{6 \times 300\left[1-\left(\frac{0}{100}\right)\right]}=1,011$ 
set $=1$ set, Tahun $2019 M=\frac{50500 \times 0,032}{6 \times 300\left[1-\left(\frac{0}{100}\right)\right]}=0,898$ set $=1$ set, Tahun $2020 M=\frac{80042 \times 0,032}{6 \times 300\left[1-\left(\frac{0}{100}\right)\right]}$ $=1,423$ set $=2$ set.

\section{Evaluasi Alternatif}

Setelah mengetahui kebutuhan jumlah mesin untuk tiap strategi, maka kini PT XYZ memiliki tiga pilihan strategi untuk mengatasi naiknya permintaan sandal, yaitu: (1)menggunakan strategi base case dengan tidak menambah jumlah mesin dan hanya menggunakan lembur untuk mengatasi permintaan sandal melebihi kapasitas yang tersedia; (2)menggunakan strategi expansionist tetap mempertahankan satu set di tahun pertama dan kedua, dan menambah satu set mesin di tahun ketiga; dan menggunakan strategi wait and see dengan tetap mempertahankan satu set di tahun pertama dan kedua, dan menambah satu set mesin di tahun ketiga.

Alternatif strategi expansionist maupun strategi wait and see menghasilkan perhitungan yang sama yaitu dengan mempertahankan satu set di tahun pertama dan kedua, dan menambah satu set mesin di tahun ketiga.

Nilai kemungkinan subjektif untuk kemungkinan terjadinya kenaikan permintaan sandal di tahun ketiga sebesar 0,3 untuk kemungkinan permintaan lebih tinggi 5\% dari peramalan (84.044 pasang sandal); 0,5 untuk permintaan sesuai dengan peramalan (80.042 pasang sandal); dan untuk permintaan lebih rendah 5\% dari peralaman (76.040 pasang sandal), dengan dasar penilaian: (1)Probabilita sebesar 0,3 diberikan untuk kemungkinan permintaan lebih tinggi $5 \%$ dari peralaman apabila perusahaan bersikap optimis nilai peramalan yang dilakukan.(2)Probabilita sebesar 0,5 diberikan untuk kemungkinan permintaan sama dengan peramalan karena peramalan telah diuji ketelitiannya.(3)Probabilita sebesar 0,2 diberikan untuk kemungkinan permintaan lebih rendah 5\% dari peramalan apabila perusahaan bersikap pesimis terhadap nilai peramalan yang dilakukan.

Dari perhitungan sebelumnya diketahui bahwa untuk memenuhi permintaan sandal di tahun ketiga (tahun 2020) sebanyak 80.042 dibutuhkan 2 set mesin (capacity cushion $0 \%$ ) yang berarti 1 set mesin akan sanggup memproduksi 40.021 pasang sandal apabila bekerja pada waktu normal (selama 8 jam per hari, 300 hari per tahun). Sedangkan apabila digunakan lembur (selama 3 jam per hari, 300 hari per minggu) maka untuk memenuhi permintaan sandal di tahun ketiga sebanyak 80.042 akan membutuhkan mesin sejumlah 2 set (capacity cushion 0\%) yang berarti 1 set mesin akan sanggup memenuhi sebanyak 15.007,875 pasang sandal.

Total keseluruhan permintaan yang sanggup dipenuhi oleh tiap alternatif:

Tabel 5. Total Permintaan Terpenuhi oleh Tiap Alternatif

\begin{tabular}{|c|c|c|c|c|c|}
\hline Alternatif & Standar & $\begin{array}{c}\text { Total } \\
\text { Standar }\end{array}$ & Lembur & $\begin{array}{c}\text { Total } \\
\text { Lembur }\end{array}$ & $\begin{array}{c}\text { Total } \\
\text { Standar+Lembur }\end{array}$ \\
\hline 2 set mesin & 40021 & 80042 & 15007,875 & 30015,750 & 110057,750 \\
\hline 1 set mesin & 40021 & 40021 & 15007,875 & 15007,875 & 55028,875 \\
\hline
\end{tabular}

Sumber: Analisis Penulis 
Agar hasil penelitian lebih sensitif terhadap perubahan faktor eksternal yang terjadi, perlu dilakukan analisis sensitivitas, yaitu memperhitungkan kemungkinan terjadinya tiga kondisi untuk tiap tahun.

Dalam penelitian ini dilakukan perhitungan estimasi cash flow untuk tiga tahun ke depan dengan kondisi permintaan lebih tinggi 5\% dari peramalan, permintaan sesuai dengan peramalan, dan permintaan lebih rendah 5\% dari peramalan, dengan asumsi tersebut cukup mewakili kombinasi kemungkinan terjadinya kondisi-kondisi lain.

\section{Estimasi Perhitungan Cash Flow}

Untuk menentukan alternatif mana yang akan memberikan hasil terbaik maka perlu perhitungan cash flow untuk mendapatkan nilai hasil dari setiap alternatif. Harga per pasang sandal adalah Rp 26.000,00. Payoff $=($ cash flow tahun $1+$ cash flow tahun $2+$ cash flow tahun 3) - investasi. Dengan demikian hasil dari setiap alternatif adalah sebagai berikut:

Tabel 6. Pay Off Strategi Expansionist

\begin{tabular}{|c|c|c|c|c|c|}
\hline $\begin{array}{c}\text { Alternatif 1 : 2 set } \\
\text { mesin di tahun } \\
\text { ketiga }\end{array}$ & $\mathbf{2 0 1 8}$ & $\mathbf{2 0 1 9}$ & $\mathbf{2 0 2 0}$ & Investasi & \multirow{2}{*}{ Payoff } \\
\cline { 2 - 6 } & $\mathrm{Rp} 212.722 .368$ & $\mathrm{Rp} 166.180 .699$ & $\mathrm{Rp} 273.692 .432$ & $\mathrm{Rp} 35.000 .000$ & $\mathrm{Rp} 617.595 .499$ \\
\hline sesuai peramalan & $\mathrm{Rp} 225.073 .284$ & $\mathrm{Rp} 176.011 .583$ & $\mathrm{Rp} 287.793 .573$ & $\mathrm{Rp} 35.000 .000$ & $\mathrm{Rp} 653.878 .440$ \\
\hline $\begin{array}{c}\text { naik 5\% dari } \\
\text { peramalan }\end{array}$ & $\mathrm{Rp} 200.371 .451$ & $\mathrm{Rp} 156.349 .816$ & $\mathrm{Rp} 259.591 .810$ & $\mathrm{Rp} 35.000 .000$ & $\mathrm{Rp} 581.313 .077$ \\
\hline $\begin{array}{c}\text { turun 5\% dari } \\
\text { peramalan }\end{array}$ & & &
\end{tabular}

Sumber: Analisis Penulis

Tabel 7. Pay Off Strategi Wait and See

\begin{tabular}{|c|c|c|c|c|c|}
\hline $\begin{array}{c}\text { Alternatif 2 : 2 set } \\
\text { mesin di tahun } \\
\text { ketiga }\end{array}$ & $\mathbf{2 0 1 8}$ & $\mathbf{2 0 1 9}$ & $\mathbf{2 0 2 0}$ & Investasi & \multirow{2}{*}{ Payoff } \\
\cline { 2 - 6 } & $\mathrm{Rp} 212.722 .368$ & $\mathrm{Rp} 166.180 .699$ & $\mathrm{Rp} 273.692 .432$ & $\mathrm{Rp} 35.000 .000$ & $\mathrm{Rp} 617.595 .499$ \\
\hline $\begin{array}{c}\text { sesuai peramalan } \\
\begin{array}{c}\text { naik 5\% dari } \\
\text { peramalan }\end{array}\end{array}$ & $\mathrm{Rp} 225.073 .284$ & $\mathrm{Rp} 176.011 .583$ & $\mathrm{Rp} 287.793 .573$ & $\mathrm{Rp} 35.000 .000$ & $\mathrm{Rp} 653.878 .440$ \\
\hline $\begin{array}{c}\text { turun 5\% dari } \\
\text { peramalan }\end{array}$ & $\mathrm{Rp} 200.371 .451$ & $\mathrm{Rp} 156.349 .816$ & $\mathrm{Rp} 259.591 .810$ & $\mathrm{Rp} 35.000 .000$ & $\mathrm{Rp} 581.313 .077$ \\
\hline
\end{tabular}

Sumber: Analisis Penulis

Tabel 8. Pay Off Strategi Base Case

\begin{tabular}{|c|c|c|c|c|c|}
\hline \multirow{2}{*}{ Alternatif 3 : 1 set mesin } & \multicolumn{3}{|c|}{ Cash Flow } & \multirow{2}{*}{ Investasi } & \multirow{2}{*}{ Payoff } \\
\hline & 2018 & 2019 & 2020 & & \\
\hline $\begin{array}{l}\text { sesuai peramalan tanpa } \\
\text { lembur }\end{array}$ & Rp140.973.848 & Rp114.844.409 & Rp91.163.682 & 0 & Rp346.981.939 \\
\hline $\begin{array}{c}\text { sesuai peramalan dengan } \\
\text { lembur }\end{array}$ & Rp182.983.103 & Rp153.986.607 & Rp145.741.423 & 0 & Rp482.711.133 \\
\hline $\begin{array}{c}\text { naik } 5 \% \text { dari peramalan } \\
\text { tanpa lembur }\end{array}$ & Rp140.973.848 & Rp114.844.409 & Rp91.163.682 & 0 & Rp346.981.939 \\
\hline $\begin{array}{c}\text { naik 5\% dari peramalan } \\
\text { dengan lembur }\end{array}$ & Rp182.477.274 & Rp159.956.565 & Rp145.291.271 & 0 & Rp487.725.110 \\
\hline $\begin{array}{c}\text { turun } 5 \% \text { dari peramalan } \\
\text { tanpa lembur }\end{array}$ & Rp140.973.848 & Rp114.844.409 & Rp91.163.682 & 0 & Rp346.981.939 \\
\hline $\begin{array}{c}\text { turun } 5 \% \text { dari peramalan } \\
\text { dengan lembur }\end{array}$ & Rp180.657.794 & Rp148.093.869 & Rp146.191.576 & 0 & Rp474.943.239 \\
\hline
\end{tabular}

Sumber: Analisis Penulis 
Daru tabel-tabel hasil perhitungan payoff di atas, apabila digambarkan dengan pohon keputusannya, maka gambarnya adalah sebagai berikut:

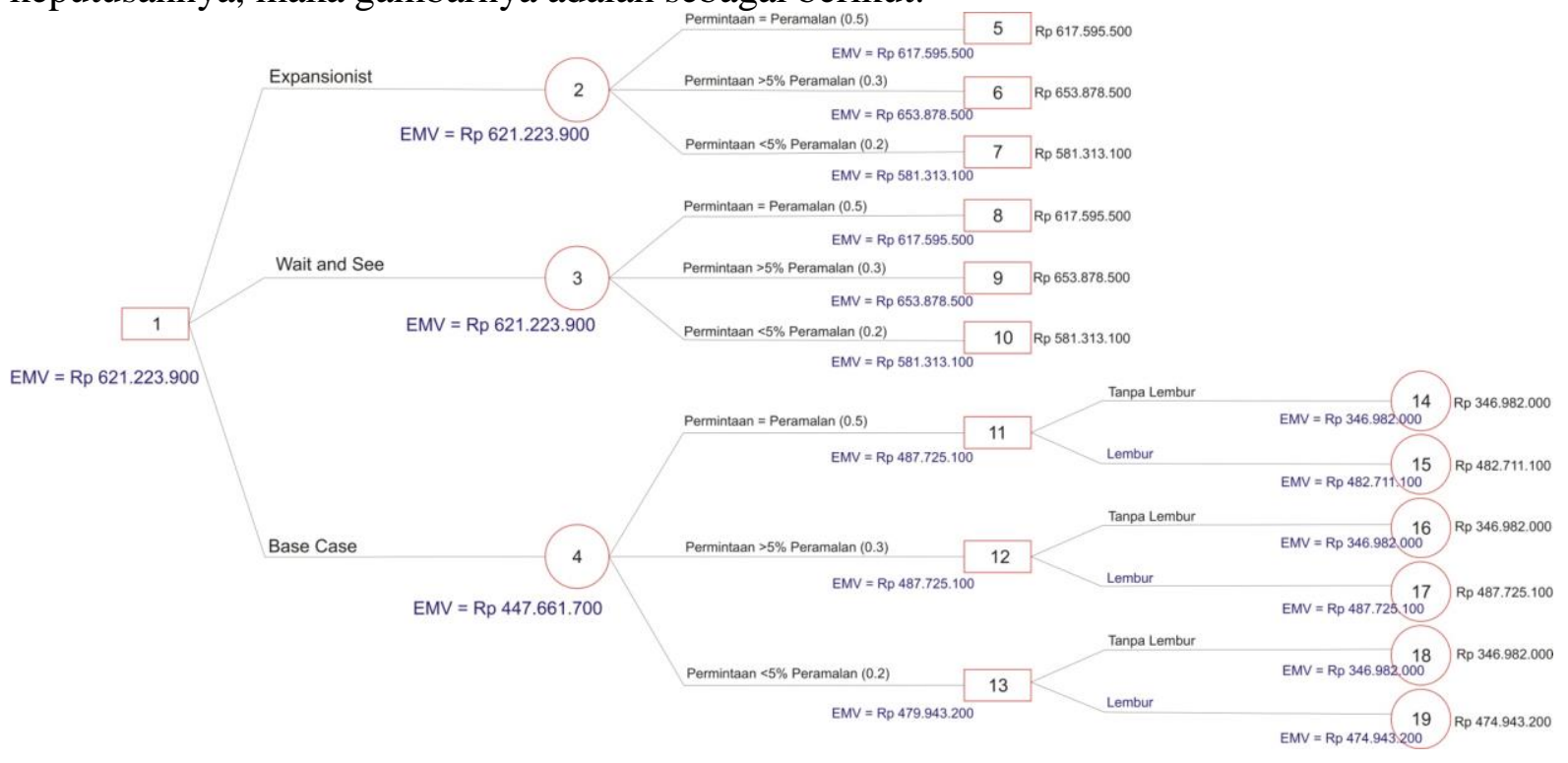

Gambar 1. Pohon Keputusan Pemilihan Strategi pada PT XYZ

Sumber: Analisis Penulis

Berdasarkan gambar 1 di atas, dapat dilihat bahwa kebijakan yang memberikan keuntungan paling besar adalah strategi expansionist dan strategi wait and see, karena kedua strategi ini menganjurkan untuk mempertahankan satu set mesin yang ada untuk tahun 20182019 dan menambah 1 set mesin baru di tahun 2020.

\section{KESIMPULAN}

Strategi yang dapat dilakukan oleh PT XYZ untuk mengatasi kekurangan kapasitasnya yaitu: (1)Menggunakan strategi expansionist atau strategi wait and see dengan tetap menggunakan satu set mesin di tahun pertama dan kedua, lalu menambah satu set di tahun ketiga. Menggunakan strategi base case, dengan tidak menambah jumlah mesin dan menggunakan waktu lembur untuk mengatasi kekurangan kapasitas. Strategi yang paling menguntungkan secara kuantitatif untuk diterapkan oleh PT XYZ adalah strategi yang memberikan hasil payoff terbesar, yaitu strategi expansionist maupun strategi wait and see. 


\section{DAFTAR PUSTAKA}

Heizer, Jay dan Render, Barry. (2011). Operations Management tenth edition. Pearson: USA.

Kusuma, Hendra. (2004). Manajemen Produksi: Perencanaan dan Pengendalian Produksi. Penerbit Andi: Yogyakarta.

Krajewski, Lee J; Ritzman, Larry P; Malhotra, Manoj K. (2010). Operations Management Processes and Supply Chains 9th Edition. Prentice Hall: New Jersey.

Rani, Asni Mustika. (2016). Meminimumkan Waktu Produksi Sandal dengan Penjadwalan Metode CDS (Studi pada CV AWMK). Jurnal Manajemen dan Bisnis (Performa) Volume XIII No.2.

Reid, R. Dan dan Sanders, Nada R. (2011). Operations Management 4th Edition. John Wiles \& Sons: USA. 